\title{
Reverse takotsubo cardiomyopathy in fulminant COVID-19 associated with cytokine release syndrome and resolution following therapeutic plasma exchange: a case-report
}

Fahad Faqihi ${ }^{1,2}$, Abdulrahman Alharthy ${ }^{1}$, Rayan Alshaya ${ }^{1}$, John Papanikolaou ${ }^{1,3}$, Demetrios J. Kutsogiannis ${ }^{4}$, Peter G. Brindley ${ }^{4}$ and Dimitrios Karakitsos ${ }^{1,3,5^{*}}$ (D)

\begin{abstract}
Background: Fulminant (life-threatening) COVID-19 can be associated with acute respiratory failure (ARF), multisystem organ failure and cytokine release syndrome (CRS). We present a rare case of fulminant COVID-19 associated with reverse-takotsubo-cardiomyopathy (RTCC) that improved with therapeutic plasma exchange (TPE).

Case presentation: A 40 year old previous healthy male presented in the emergency room with 4 days of dry cough, chest pain, myalgias and fatigue. He progressed to ARF requiring high-flow-nasal-cannula (flow: $60 \mathrm{~L} / \mathrm{minute}$, fraction of inspired oxygen: 40\%). Real-Time-Polymerase-Chain-Reaction (RT-PCR) assay confirmed COVID-19 and chest X-ray showed interstitial infiltrates. Biochemistry suggested CRS: increased C-reactive protein, lactate dehydrogenase, ferritin and interleukin-6. Renal function was normal but lactate levels were elevated. Electrocardiogram demonstrated non-specific changes and troponin-l levels were slightly elevated. Echocardiography revealed left ventricular (LV) basal and midventricular akinesia with apex sparing (LV ejection fraction: $30 \%)$ and depressed cardiac output $(2.8 \mathrm{~L} / \mathrm{min})$ consistent with a rare variant of stress-related cardiomyopathy: RTCC. His ratio of partial arterial pressure of oxygen to fractional inspired concentration of oxygen was $<120$. He was admitted to the intensive care unit (ICU) for mechanical ventilation and vasopressors, plus antivirals (lopinavir/ritonavir), and prophylactic anticoagulation. Infusion of milrinone failed to improve his cardiogenic shock (day-1). Thus, rescue TPE was performed using the Spectra Optia ${ }^{\text {TM }}$ Apheresis System equipped with the Depuro D2000 Adsorption Cartridge (Terumo BCT Inc., USA) without protective antibodies. Over 5 days he received daily TPE (each lasting 4 hours). His lactate levels, oxygenation, and LV function normalized and he was weaned off vasopressors. His inflammation markers improved, and he was extubated on day-7. RT-PCR was negative on day-17. He was discharged to home isolation in good condition.

\footnotetext{
* Correspondence: karakitsosdimitrios@gmail.com; d.karakitsos@ksmc.med.sa

'Critical Care Department, King Saud Medical City, Riyadh, Kingdom of Saudi Arabia

${ }^{3}$ Department of Medicine, School of Medicine, University of South Carolina, Columbia, SC, USA

Full list of author information is available at the end of the article
}

C C The Author(s). 2020 Open Access This article is licensed under a Creative Commons Attribution 4.0 International License, which permits use, sharing, adaptation, distribution and reproduction in any medium or format, as long as you give appropriate credit to the original author(s) and the source, provide a link to the Creative Commons licence, and indicate if changes were made. The images or other third party material in this article are included in the article's Creative Commons licence, unless indicated otherwise in a credit line to the material. If material is not included in the article's Creative Commons licence and your intended use is not permitted by statutory regulation or exceeds the permitted use, you will need to obtain permission directly from the copyright holder. To view a copy of this licence, visit http://creativecommons.org/licenses/by/4.0/ The Creative Commons Public Domain Dedication waiver (http://creativecommons.org/publicdomain/zero/1.0/) applies to the data made available in this article, unless otherwise stated in a credit line to the data. 
(Continued from previous page)

Conclusion: Stress-cardiomyopathy may complicate the course of fulminant COVID-19 with associated CRS. If inotropic therapy fails, TPE without protective antibodies may help rescue the critically ill patient.

Keywords: COVID-19, Reverse takotsubo cardiomyopathy, Echocardiography, Cardiogenic shock, Cytokine release syndrome, Therapeutic plasma exchange, Case-report

\section{Background}

The novel coronavirus SARS-CoV-2 disease (COVID19) has emerged in Wuhan city, Hubei province, in China, and has spread worldwide [1]. A minority of patients can develop life-threatening disease, which is characterized by acute respiratory distress syndrome (ARDS), sepsis, multi-system organ failure (MSOF), thromboembolic disease, neurological manifestations, and associated cytokine release syndrome (CRS) [2, 3]. Cardiac involvement in COVID-19 includes arrhythmia (atrial fibrillation, ventricular tachyarrhythmia and fibrillation), cardiac injury [elevated troponin I and creatine kinase (CK) levels], fulminant myocarditis, heart failure, and pulmonary embolism (PE) [4-9]. The etiology is assumed multifactorial, including direct viral myocardial injury, hypoxia, hypotension, ACE2-receptor downregulation, drug toxicity, CRS, and endogenous catecholamine over-discharge [4-9]. Of note, the histopathologic findings in autopsies of COVID-19 patients have not definitively confirmed myocarditis [10-12].

Recent studies have suggested the occurrence of takotsubo cardiomyopathy (TTC) [13-17], and reverse takotsubo cardiomyopathy (RTCC) [18] in patients with COVID-19. The underlying pathophysiology of TTC (or neurogenic stress cardiomyopathy) is believed multifactorial with catecholamine-mediated cardiotoxicity the most likely mechanism [19-24]. Although usually reversible [25-28], TCC can cause severe left ventricular (LV) wall dysfunction (with an echocardiographic picture of apical ballooning), acute heart failure, cardiogenic shock, LV outflow tract obstruction, thrombus formation, and arrhythmias [29]. Reverse TTC (RTTC) is a rare variant, which is characterized by basal and midventricular LV akinesia plus apical sparing [18, 27]. Herein, we present a patient with life-threatening COVID-19 who had ARDS, CRS and RTTC [30]. These resolved with therapeutic plasma exchange (TPE) without protective antibodies. TPE has been previously used in patients with severe sepsis, MSOF and SARS-CoV with variable results [31-35].

\section{Case presentation}

A 40 year old, previous healthy, male presented to the emergency department with 4 days of dry cough, chest pain, myalgia and progressive fatigue. Physical examination was normal apart from decreased breath sounds at the lung bases and mild tachypnea. Vital signs were within normal limits. Within 2 hours, however, the patient desaturated (Pulse Oximeter Oxygen Saturation: 86\%) and became dyspneic; hence he received high flow nasal cannula (HFNC; flow: $60 \mathrm{~L} /$ minute, fraction of inspired oxygen 40\%) [36-38]. Laboratory results were within normal limits apart from lymphocytopenia $\left(0.55 \times 10^{9} / \mathrm{L}\right.$, normal: $\left.1.1-3.2 \times 10^{9} / \mathrm{L}\right)$, and increased C-reactive protein [(CRP) $82.5 \mathrm{mg} /$ liter, normal: $0-7 \mathrm{mg} /$ liter], lactate dehydrogenase [(LDH) 840 units/ liter, normal: 100 to 190 units/liter], ferritin $(3101 \mathrm{ng} / \mathrm{ml}$, normal: $23-336 \mathrm{ng} / \mathrm{ml}$ ), and interleukin-6 [(IL-6) $398 \mathrm{pg} / \mathrm{ml}$, normal: $1-7 \mathrm{pg} / \mathrm{mL}$ ). The increased values of the inflammation biomarkers laboratory suggested the development of CRS, which is further defined in Table 1 (Additional file 1) $[39,40]$. CK was slightly increased (422 units/liter, normal: 22 to 198 units/liter) but renal function was normal. Ddimer levels were normal but troponin-I was slightly elevated $(4.7 \mathrm{ng} / \mathrm{ml}$, normal: $<0.04 \mathrm{ng} / \mathrm{ml})$. Electrocardiogram showed sinus tachycardia (115 beats/min) and non-specific ST-segment and T-wave abnormalities in the precordial leads. Nasopharyngeal swabs confirmed COVID-19 by RealTime-Polymerase-Chain-Reaction (RT-PCR) assays (Roche, Basel, Switzerland) [41, 42]. Chest X-ray showed interstitial infiltrates and consolidations (Fig. 1). Transthoracic twodimensional echocardiography revealed LV basal and midventricular akinesia with apical sparing (Fig. 2). LV ejection fraction was approximately $30 \%$ and cardiac output was depressed $(2.8 \mathrm{~L} / \mathrm{min})$ [43-45]. The slightly elevated troponin I levels and the echocardiographic findings suggested RTCC $[13-18,25-28]$. The right ventricle was not significantly dilated, and no LV outflow tract obstruction, thrombus or pericardial effusion was evident. Despite the prompt application of HFNC the patient continued to deteriorate due to cardiogenic shock (Video 1; Additional files 1 and 2), with increasing noradrenaline requirements $(1.5 \mathrm{mcg} / \mathrm{kg} / \mathrm{min})$ and serum lactate $(5.6 \mathrm{mmol} / \mathrm{L})$. We could not perform computed tomography angiography/coronary angiography due to his instability; hence, we could not definitively exclude pathologies such as aortic dissection, pulmonary embolism (PE), myocarditis or coronary artery disease (CAD). However, these diagnoses were less likely given the echocardiographic features of RTCC.

The patient was subsequently intubated and admitted to the intensive care unit (ICU), where his ratio of partial arterial pressure of oxygen to fractional inspired concentration of oxygen $\left(\mathrm{PaO}_{2} / \mathrm{FiO}_{2}\right)$ was $<120$. He received 
ARDS-net ventilation, lung recruitment, prone positioning, empiric antiviral therapy (lopinavir /ritonavir: 400/ $100 \mathrm{mg}$ twice daily for 2 weeks) [46], and prophylactic anticoagulation (enoxaparin plus intermittent pneumatic compression) [10, 47-50]. Upon ICU admission (day-1), he required increasing norepinephrine $(1.8 \mathrm{mcg} / \mathrm{kg} / \mathrm{min})$ due to worsening cardiogenic shock. Dobutamine was considered but held as this exogenous catecholamineinotrope can aggravate stress-cardiomyopathy [13-18]. Levosimendan, a non-catecholamine inotrope, which shows promise in TCC, was not available [51]. Instead, intravenous milrinone (non-catecholamine inotrope) was initiated: $50 \mathrm{mcg} / \mathrm{kg}$ loading dose over $10 \mathrm{~min}$; then $0.375 \mathrm{mcg} / \mathrm{kg} / \mathrm{min}$. It was stopped due to tachyarrhythmia [52]. Intravenous beta-blocker esmolol $(0.02 \mathrm{mg} / \mathrm{kg} / \mathrm{min})$ was titrated to a heart-rate $\leq 95$ beats/min (to protect the heart from catecholamine storm and counteracting tachycardia) [53], but was stopped due to bronchospasm.

Because inotropic therapy was failing, we recruited the patient into our study investigating the potential role of TPE as rescue therapy in life-threatening COVID-19 associated with CRS [40]. Following informed consent from his legal representative, rescue TPE was initiated on post-ICU admission day-1, using the Spectra Optia ${ }^{\text {Tm }}$ Apheresis System equipped with the Depuro D2000 Adsorption Cartridge (Terumo BCT Inc., USA) [32, 33]. A dose of 1.5 plasma volumes was used for the first dose then one plasma volume daily for a total of five doses (4 hours each day). Spectra Optia ${ }^{\text {Tx }}$ Apheresis System employs an acid-citrate dextrose anticoagulant as per Kidney Disease Improving Global Outcomes 2019 guidelines [54]. Intravenous hydrocortisone $100 \mathrm{mg}$ and chlorpheniramine $10 \mathrm{mg}$ were administered as adjunctive treatment during TPE to reduce any potential side-effects. Plasma was replaced with albumin 5\%. Our patient did not have any coagulopathy or elevated levels of D-dimer. No side effects due to TPE were recorded (i.e., allergies, infection, and coagulopathy). Daily negative fluid balance was achieved.
After only the 2nd TPE session (day-2) LV function gradually improved (Fig. 2) although interstitial lung edema was still present (Video 2; Additional files 1 and 3). After the 3rd TPE session (day-3), he was weaned off vasopressors, and his lactate, blood pressure and LV function normalized. After completion of TPE (day-5), $\mathrm{PaO}_{2} / \mathrm{FiO}_{2}$ ratio exceeded 300 , his chest X-ray showed less infiltrates (Fig. 1), his lymphocyte count increased (from 0.55 to $1.1 \times 10^{9} / \mathrm{l}$ ) and his CRP (82.5 to $10.1 \mathrm{mg} /$ liter), LDH (840 to 140 units/liter), ferritin (3101 to 234 $\mathrm{ng} / \mathrm{ml}$ ) and IL-6 (398 to $11 \mathrm{pg} / \mathrm{ml}$ ) decreased. He was extubated on day-7 post-ICU admission. RT-PCR test and microbiology were negative on day-17. All work-up for systemic and other viral diseases was negative. The patient was pleased with his therapy but refused any additional diagnostic testing. He was discharged to home isolation in good condition, and has been followed by our outreach team for a period of 2 months.

\section{Discussion and conclusions}

This rare case of RTCC in COVID-19 comes from our ongoing study of TPE as rescue therapy in life threatening COVID-19 with associated CRS (ISRCTN21363594) [40]. TTC may present as severe LV systolic dysfunction after emotional stress (primary subtype) or critical illness (secondary subtype). Although usually transient, TTC can manifest as cardiogenic shock and be associated with lower short- and long- term survival [13-29]. Transient stress-cardiomyopathy has been reported in COVID-19 [13-18]. An overlapping picture of myocarditis and RTCC has been reported too [18]. Our patient had typical clinical and echocardiographic features of RTCC [13-29]. We could not perform a full diagnostic work-up due to the severity of COVID-19; hence, we could not definitively exclude other cardiovascular pathologies such as aortic dissection, PE, myocarditis or CAD. However, his echocardiographic features and biochemical abnormalities make these diagnoses less likely.

Importantly, we cannot conclude that TPE definitively rescued the patient. Potentially, his clinical state and

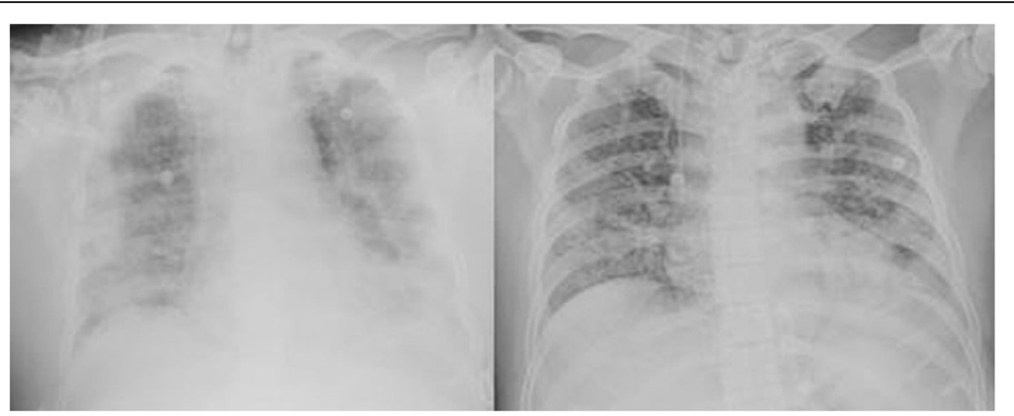

Fig. 1 Portable chest X-rays of our COVID-19 patient depicting interstitial infiltrates and consolidations (day-1) prior to therapeutic plasma exchange (TPE) (left panel); and after five sessions of TPE (day-5) showing gradual improvement (right panel) 


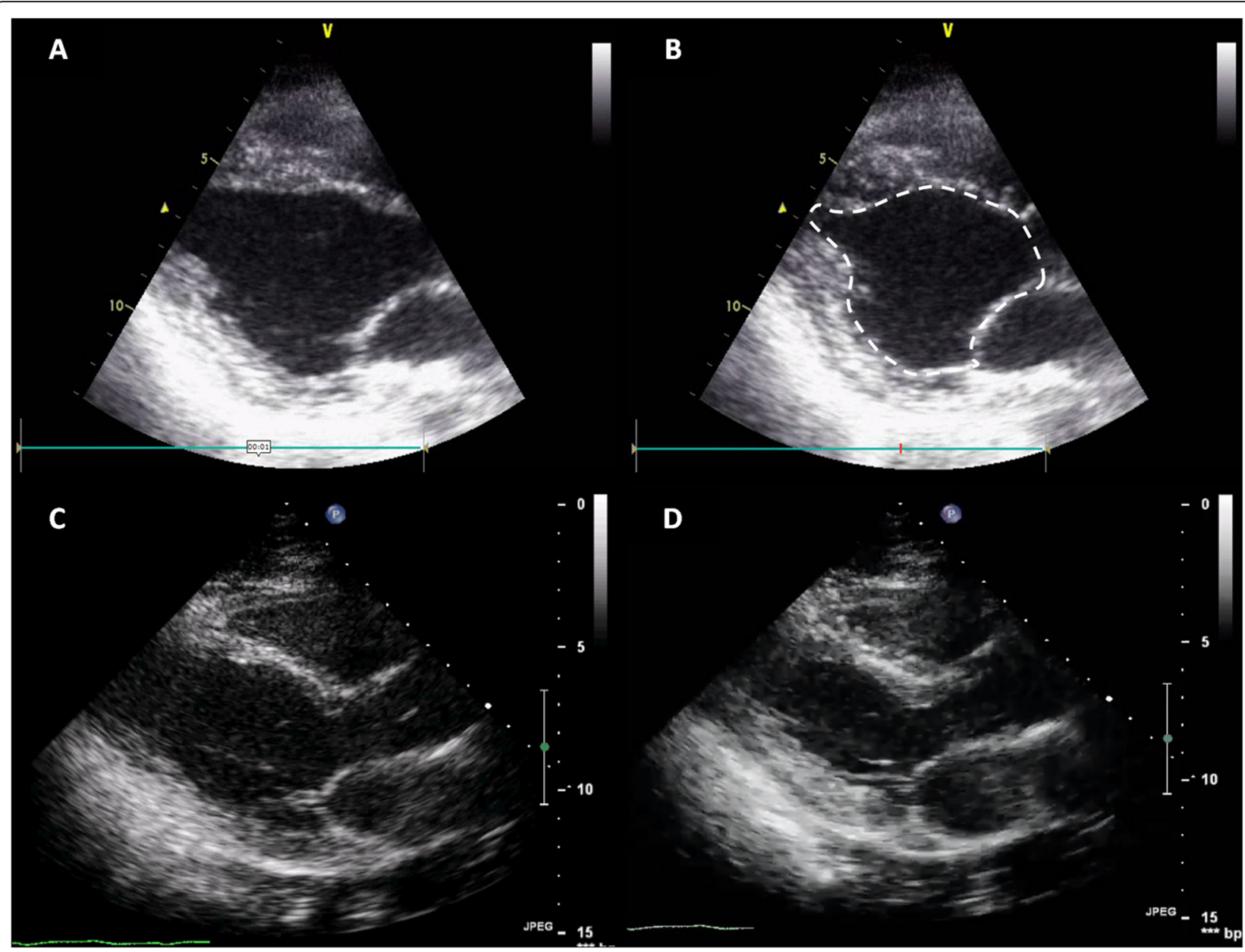

Fig. 2 Two-dimensional bedside echocardiography (parasternal long-axis views) depicting the anteroseptal and posterolateral walls of the left ventricle (LV) in our COVID-19 patient (day-1). End-diastolic (a) and end-systolic (b) frames illustrating basal and midventricular LV akinesia with apical sparing and an "ace of spades" configuration typical of reverse takotsubo cardiomyopathy (white dashed line; frame B). End-diastolic (c) and end-systolic (d) frames after two plasma exchange sessions (day-2) showing gradual recovery of the segmental LV wall motion abnormalities

biochemical aberrations could have improved without TPE; although his clinical picture was grave, and other therapies largely failed. The management of acute heart failure due to TTC, especially in patients with life-threatening COVID19, is challenging. Patients with stress-cardiomyopathy often do not improve with fluid administration because their LV operates mainly within the flat portion of the Frank-Starling curve. This means aggressive volume resuscitation can cause pulmonary edema and hemodynamic compromise. In TCC, adrenergic stimulation is high, thus exogenous catecholamine-inotropes (i.e., dopamine, dobutamine, and norepinephrine) can further impair cardiac contractility: by exacerbating neurocardiogenic injury and calcium overload in an already stressed myocardium. The use of non-catecholamine inotropes (i.e., milrinone and levosimendan) may be beneficial providing no LV outflow obstruction [13-18, 51-53]. Beta-blockers are important in the management of TTC complicated by LV outflow tract obstruction [55]; however, their use in RTTC without intraventricular pressure gradient remains controversial [56]. Our patient did not have LV outflow tract obstruction; however, using the beta-1 cardio-selective blocker esmolol (half-life: $9 \mathrm{~min}$ ) has been encouraged in TTC. Fortunately this short acting agent can be discontinued if adverse effects occur (i.e., impaired LV cardiac contractility, blood pressure, and central hemodynamics) [57]. Recently, an inhospital score has been suggested to stratify TTS patient's risk by the German and Italian Stress Cardiomyopathy (GEIST) registry [58]. That study concluded that independent predictors of in-hospital complications of TTC were: male sex, history of neurologic disorder, RV involvement, and decreased LVEF (GEIST score). Hence, our patient would be at intermediate risk being a male with an LVEF of $30 \%$, and requiring ICU admission. Notwithstanding, our patient also had lifethreatening COVID-19, which might be considered an additional risk factor complicating acute heart failure due to stress-cardiomyopathy. 
This is the first time, to our knowledge, that TPE has been reported as rescue therapy for cardiogenic shock due to stress-cardiomyopathy in serious COVID-19. We employed TPE with an adsorption cartridge containing activated uncoated coconut shell (carbon granules) charcoal $(100 \mathrm{~g})$, and the nonionic resins Amberlite XAD$7 \mathrm{HP}$ and Amberchrom GC300C [20, 28]. These can remove interferon-gamma, interleukins $-3,-10,-1 \mathrm{~B},-6$, -8 , and tumor necrosis factor-alpha [18-23]. Although a full cytokine panel was not available in our institution at that time, TPE resulted in pertinent biochemical improvements: decreased inflammatory mediators (CRP, LDH, and ferritin), IL-6, and increased lymphocytic count [30-40]. Elevated inflammation markers are associated with more severe COVID-19, and elevated IL-6 is associated with worse CRS [30-40]. This is why tocilizumab, a monoclonal antibody against IL-6, has been tried in severe COVID-19, albeit with conflicting results [59-62]. In our institution, tocilizumab was not available, at that time. Similarly, the antiviral remdesevir and convalescent plasma transfusion (containing a high concentration of neutralizing antibodies) have shown promise in treating serious COVID-19 but results are inconclusive [63-66]. In a recent, randomized control trial, which has been performed among patients with severe or life-threatening COVID-19, convalescent plasma therapy has been added to standard anti-COVID-19 treatment. However, when compared with standard treatment alone, convalescent plasma therapy was not associated with a significant clinical improvement within 28 days of hospitalization [67]. Moreover, the natural course of COVID-19 viremia and the developing antibodies titers remains uncertain [68-70], and convalescent plasma therapy is not currently widely available.

This case-report has limitations, which prevent its generalizability. First, patients with cardiogenic shock and absence of LV outflow obstruction might benefit from an intra-aortic balloon pump, but this was not available [71]. Also, cardiac magnetic resonance imaging was not performed to exclude myocarditis [14-18] as our follow-up period was limited to 2 months. Importantly, RTCC (as well as COVID-19) can resolve with no more than supportive therapy. In other words we cannot definitively confirm that TPE rescued the patient, only that their illness severity led us to apply TPE, and the patient survived. Other limitations include that in trying to pinpoint the role played by TPE we cannot exclude other aggressive life support plus empiric therapies. The effects of all of these on biochemistry, cardiac function and survival is unclear $[1,2,4-18,72]$. Even if TPE is beneficial, the optimal TPE regime is unclear because the course of COVID-19 viremia has yet to be elucidated [63-68]. Accordingly, we speculate that prompt TPE initiation mitigated full-blown CRS, given the associated reduction in our patient's elevated IL-6 [30-35, 59-62]. Presumably, at an early stage of COVID-19 dysregulated immune system pathology may be more important than viral replication per se [73]. However, it is unknown exactly how reducing COVID-19 associated CRS works in improving stress-cardiomyopathy. It could have a direct effect (i.e., by reducing cardiac inflammation) or work indirectly (i.e., improving oxygenation, LV filling pressures and reducing the stress of critical illness).

In conclusion, stress-cardiomyopathy and related cardiogenic shock can complicate fulminant COVID-19 with associated CRS. If usual therapies fail, rescue TPE (without protective antibodies) could be considered and warrants further study.

\section{Supplementary information}

Supplementary information accompanies this paper at https://doi.org/10. 1186/s12872-020-01665-0.

\section{Additional file 1. \\ Additional file 2. \\ Additional file 3. \\ Additional file 4 .}

\section{Abbreviations}

TCC: Takotsubo cardiomyopathy; RTCC: Reverse takotsubo cardiomyopathy; COVID-19: SARS-CoV-2 disease; TPE: Therapeutic plasma exchange;

ICU: Intensive care unit; CRS: Cytokine release syndrome; ARDS: Acute respiratory distress syndrome; MSOF: Multi-system organ failure; CRP: Creactive protein; LDH: Lactate dehydrogenase; IL-6: Interleukin-6; LV: Left ventricular; RT-PCR: Real-time-polymerase-chain-reaction; HFNC: High flow nasal cannula; $\mathrm{PaO}_{2} / \mathrm{FiO}_{2}$ ratio: Partial arterial pressure of oxygen to fractional inspired concentration of oxygen ratio; PE: Pulmonary embolism;

CAD: Coronary artery disease

\section{Acknowledgments}

Not applicable.

\section{Authors' contributions}

FF, AA, and RA treated the patient, collected the data and drafted equally the manuscript. JP and DK provided expert echocardiographic consultation and drafted equally the manuscript. DJK, PGB reviewed the data and drafted equally the manuscript. The final version of the manuscript was approved by all authors.

\section{Funding}

The study is funded by King Saud Medical City.

\section{Availability of data and materials}

The datasets used and/or analyzed during the current study are available from the corresponding author on reasonable request.

\section{Ethics approval and consent to participate}

The study was approved by the Institutional Review Board of King Saud Medical City, Riyadh, Kingdom of Saudi Arabia, protocol/serial number: H-01R-053, IORG0010374, H1R1-29-Apr20-01. Written informed consent is obtained by all eligible patients or their legal representatives. The study is also registered at ISRCTN (ISRCTN21363594; doi.10.1186/ ISRCTN21363594).

\section{Consent for publication}

Written informed consent was obtained from the patient for publication of this case report and any accompanying images. A copy of the written consent is available for review by the Editor-in-Chief of this journal. 


\section{Competing interests}

The authors declare that they have no competing interests.

\section{Author details}

${ }^{1}$ Critical Care Department, King Saud Medical City, Riyadh, Kingdom of Saudi Arabia. ${ }^{2}$ Critical Care Department, Al Imam Abdulrahman Al Feisal Hospital, Riyadh, Kingdom of Saudi Arabia. ${ }^{3}$ Department of Medicine, School of Medicine, University of South Carolina, Columbia, SC, USA. ${ }^{4}$ Department of Critical Care, Faculty of Medicine and Dentistry, The University of Alberta, Edmonton, AB, Canada. ${ }^{5}$ Critical Care Department, Keck Medical School, USC, Los Angeles, CA, USA.

Received: 15 June 2020 Accepted: 10 August 2020

Published online: 26 August 2020

\section{References}

1. Guan WJ, Ni ZY, Hu Y, et al. Clinical characteristics of coronavirus disease 2019 in China. China Medical Treatment Expert Group for Covid-19. N Engl J Med. 2020;382(18):1708-20.

2. Zhou F, Yu T, Du R, et al. Clinical course and risk factors for mortality of adult inpatients with COVID-19 in Wuhan, China: a retrospective cohort study. Lancet. 2020;395(10229):1054-62

3. Zhang Y, Xiao M, Zhang S, et al. Coagulopathy and Antiphospholipid antibodies in patients with Covid-19. N Engl J Med. 2020;382(17):e38. https://doi.org/10.1056/NEJMc2007575 Epub 2020 Apr 8.

4. Kochi AN, Tagliari AP, Forleo GB, Fassini GM, Tondo C. Cardiac and arrhythmic complications in patients with COVID-19. J CardiovasC Electrophysiol. 2020;31(5):1003-8.

5. Inciardi RM, Lupi L, Zaccone G, et al. Cardiac involvement in a patient with coronavirus disease 2019 (COVID-19). JAMA Cardiol. 2020;5(7):1-6. https:// doi.org/10.1001/jamacardio.2020.1096.

6. Zeng JH, Liu YX, Yuan J, et al. First case of COVID-19 complicated with fulminant myocarditis: a case report and insights. Infection. 2020;10:1-5.

7. Guzik TJ, Mohiddin SA, Dimarco A, et al. COVID-19 and the cardiovascular system: implications for risk assessment, diagnosis, and treatment options. Cardiovasc Res. 2020;116:Cvaa106.

8. Akhmerov A, Marbán E. COVID-19 and the heart. Circ Res. 2020;126(10): 1443-55.

9. Driggin E, Madhavan MV, Bikdeli B, et al. Cardiovascular considerations for patients, health care workers, and health systems during the COVID-19 pandemic. J Am Coll Cardiol. 2020;75(18):2352-71.

10. Menter T, Haslbauer JD, Nienhold R, et al. Post-mortem examination of COVID19 patients reveals diffuse alveolar damage with severe capillary congestion and variegated findings of lungs and other organs suggesting vascular dysfunction. Histopathology. 2020. https://doi.org/10.1111/his.14134 in press.

11. Deshpande C. Thromboembolic findings in COVID-19 autopsies: pulmonary thrombosis or embolism? Ann Intern Med. 2020. https://doi.org/10.7326/ M20-3255.

12. Fox SE, Akmatbekov A, Harbert JL, Li G, Quincy Brown J, Vander Heide RS. Pulmonary and cardiac pathology in African American patients with COVID19: an autopsy series from New Orleans. Lancet Respir Med. 2020;8(7):681-6. https://doi.org/10.1016/S2213-2600(20)30243-5.

13. Chadha S. COVID-19 pandemic's anxiety induced Tako-tsubo cardiomyopathy. QJM. 2020;113(7):488-90. https://doi.org/10.1093/qjmed/ hcaa135.

14. Nguyen D, Nguyen T, De Bels D, Castro Rodriguez J. A case of Takotsubo cardiomyopathy with COVID 19. Eur Heart J Cardiovasc Imaging. 2020: jeaa152. https://doi.org/10.1093/ehjci/jeaa152.

15. Roca E, Lombardi C, Campana M, Vivaldi O, Bigni B, Bertozzi B, Passalacqua G. Takotsubo syndrome associated with COVID-19. Eur J Case Rep Intern Med. 2020;7(5):001665

16. Meyer P, Degrauwe S, Van Delden C, Ghadri JR, Templin C. Typical takotsubo syndrome triggered by SARS-CoV-2 infection. Eur Heart J. 2020; 41(19):1860.

17. Minhas AS, Scheel P, Garibaldi B, et al. Takotsubo syndrome in the setting of COVID-19 infection. JACC Case Rep. 2020;2(9):1321-5. https://doi.org/10. 1016/j.jaccas.2020.04.023.

18. Sala S, Peretto G, Gramegna M, et al. Acute myocarditis presenting as a reverse Tako-Tsubo syndrome in a patient with SARS-CoV-2 respiratory infection. Eur Heart J. 2020;41(19):1861-2.
19. Lyon AR, Rees PS, Prasad S, Poole-Wilson PA, Harding SE. Stress (Takotsubo) cardiomyopathy - a novel pathophysiological hypothesis to explain catecholamine-induced acute myocardial stunning. Nat Clin Pract Cardiovasc Med. 2008:5:22-9.

20. Ibanez B, Choi BG, Navarro F, Farre J. Tako-tsubo syndrome: a form of spontaneous aborted myocardial infarction? Eur Heart J. 2006:27:1509-10.

21. Nojima Y, Kotani J. Global coronary artery spasm caused Takotsubo cardiomyopathy. J Am Coll Cardiol. 2010;55:e17.

22. Masuda T. Sympathetic nervous activity and myocardial damage immediately after subarachnoid hemorrhage in a unique animal model: Stroke. 2002;33:1671-6.

23. Buchholz S, Ward MR, Bhindi R, Nelson Gl, Figtree GA, Grieve SM. Cardiac thrombi in stress (Tako-tsubo) cardiomyopathy: more than an apical issue? Mayo Clin Proc. 2010;85:863.

24. Paur H, Wright PT, Sikkel MB, et al. High levels of circulating epinephrine trigger apical cardiodepression in a $\beta 2$-adrenergic receptor/Gi-dependent manner: a new model of Takotsubo cardiomyopathy. Circulation. 2012; 126(6):697-706.

25. Bybee KA, Prasad A. Stress-related cardiomyopathy syndromes. Circulation. 2008;118(4):397-409.

26. Núñez-Gil IJ, Almendro-Delia MM, Andrés MM, RETAKO investigators, et al. Secondary forms of Takotsubo cardiomyopathy: a whole different prognosis. Eur Heart J. 2016:5(4):308-16.

27. Belliveau DD, De $\mathrm{S}$. Reverse Takotsubo cardiomyopathy following exogenous epinephrine administration in the early postpartum period. Echocardiography. 2016;33(7):1089-91.

28. Elkayam UU, Jalnapurkar SS, Barakkat MN, Khatri N, et al. Pregnancy-associated acute myocardial infarction: a review of contemporary experience in 150 cases between 2006 and 2011. Circulation. 2014;129(16):1695-702.

29. Templin C, Ghadri JR, Diekmann J, et al. Clinical features and outcomes of Takotsubo (stress) cardiomyopathy. N Engl J Med. 2015;373:929-38.

30. Puja M, McAuley Daniel F, Brown M, et al. COVID-19: consider cytokine storm syndromes and immunosuppression. Lancet. 2020;395(10229):1033-4.

31. Patel $P$, Nandwani $V$, Vanchiere J, et al. Use of therapeutic plasma exchange as a rescue therapy in $2009 \mathrm{pH} 1 \mathrm{~N} 1$ influenza A--an associated respiratory failure and hemodynamic shock. Pediatr Crit Care Med. 2011;12(2):e87-9.

32. https://www.fda.gov/media/136837/download: D2000 Cartridge Operation Manual for Use of D2000 with the Terumo Spectra Optia ${ }^{\text {TM }}$ Apheresis System; for use in the U.S. under FDA EUA200148: Authorization for Emergency Use in patients with COVID-19 admitted to the ICU with confirmed or imminent respiratory failure.

33. Knaup H, Stahl K, Schmidt BMW, et al. Early therapeutic plasma exchange in septic shock: a prospective open-label nonrandomized pilot study focusing on safety, hemodynamics, vascular barrier function, and biologic markers. Crit Care. 2018:22:285

34. Dellinger RP, Bagshaw SM, Antonelli M, EUPHRATES Trial Investigators, et al. Effect of targeted Polymyxin B Hemoperfusion on 28-day mortality in patients with septic shock and elevated endotoxin level: the EUPHRATES randomized clinical trial. JAMA. 2018;320(14):1455-63.

35. Klein DJ, Foster D, Walker PM, Bagshaw SM, Mekonnen H, Antonelli M. Polymyxin B hemoperfusion in endotoxemic septic shock patients without extreme endotoxemia: a post hoc analysis of the EUPHRATES trial. Intensive Care Med. 2018:44(12):2205-12.

36. Wu Z, McGoogan JM. Characteristics of and important lessons from the coronavirus disease 2019 (COVID-19) outbreak in China: summary of a report of 72314 cases from the Chinese center for disease control and prevention. JAMA. 2020. https://doi.org/10.1001/jama.2020.2648.

37. Alhazzani W, Moller MH, Arabi YM, Loeb M, Gong MN, Fan E, et al. Surviving Sepsis campaign: guidelines on the management of critically ill adults with coronavirus disease 2019 (COVID-19). Intensive Care Med. 2020:46:854-87.

38. Yang $X, Y u Y, X u$ J, et al. Clinical course and outcomes of critically ill patients with SARS-CoV-2 pneumonia in Wuhan, China: a single-centered, retrospective, observational study. Lancet Respir Med. 2020;8:475-81.

39. Azkur AK, Akdis M, Azkur D, et al. Immune response to SARS-CoV-2 and mechanisms of immunopathological changes in COVID-19. Allergy. 2020;75: 1564-81.

40. Faqihi F, Alharthy A, Alodat M, et al. A pilot study of therapeutic plasma exchange for serious SARS CoV-2 disease (COVID-19): a structured summary of a randomized controlled trial study protocol. Trials. 2020;21:506

41. Chan JF, Yip CC, To KK, et al. Improved molecular diagnosis of COVID-19 by the novel, highly sensitive and specific COVID-19-RdRp/Hel real-time reverse 
transcription-PCR assay validated in vitro and with clinical specimens. J Clin Microbiol. 2020;58(5):e00310-20. https://doi.org/10.1128/JCM.00310-20.

42. Corman VM, Landt O, Kaiser M, et al. Detection of 2019 novel coronavirus (2019-nCoV) by real-time RT-PCR. Euro Surveill. 2020;25(3):pii2000045.

43. Douglas PS, Khandheria B, Stainback RF, et al. ACCF/ASE/ACEP/ASNC/SCAl/ SCCT/ SCMR 2007 appropriateness criteria for transthoracic and transesophageal echocardiography: a report of the American College of Cardiology Foundation Quality Strategic Directions Committee Appropriateness Criteria Working Group, American Society of Echocardiography, American College of Emergency Physicians, American Society of Nuclear Cardiology, Society for Cardiovascular Angiography and Interventions, Society of Cardiovascular Computed Tomography, and the Society for Cardiovascular Magnetic Resonance endorsed by the American College of Chest Physicians and the Society of Critical Care Medicine. J Am Coll Cardiol. 2007:50:187-204.

44. Lang RM, Bierig M, Devereux RB, et al. Recommendations for chamber quantification: a report from the American Society of Echocardiography's guidelines and standards committee and the chamber quantification writing group, developed in conjunction with the European Association of Echocardiography, a branch of the European Society of Cardiology. J Am Soc Echocardiogr. 2005;18:1440-63.

45. Noritomi DT, Vieira ML, Mohovic T, et al. Echocardiography for hemodynamic evaluation in the intensive care unit. Shock. 2010;34(Suppl 1):59-62.

46. Cao B, Wang $Y$, Wen $D$, et al. A trial of Lopinavir-ritonavir in adults hospitalized with severe Covid-19. N Engl J Med. 2020;382(19):1787-99.

47. Thachil J, et al. ISTH interim guidance on recognition and management of coagulopathy in COVID-19. J Thromb Haemost. 2020;18:1023-6.

48. Wichmann D, Sperhake JP, Lütgehetmann M, et al. Autopsy findings and venous thromboembolism in patients with COVID-19. Ann Intern Med. 2020:M20-2003. https://doi.org/10.7326/M20-2003.

49. Hékimian $\mathrm{G}$, Lebreton $\mathrm{G}$, Bréchot $\mathrm{N}$, et al. Severe pulmonary embolism in COVID-19 patients: a call for increased awareness. Crit Care. 2020;24:274

50. Fraissé $M$, Logre E, Pajot $\mathrm{O}$, et al. Thrombotic and hemorrhagic events in critically ill COVID-19 patients: a French monocenter retrospective study. Crit Care. 2020;24:275.

51. Papanikolaou J, Tsolaki V, Makris D, Zakynthinos E. Early Levosimendan administration may improve outcome in patients with subarachnoid hemorrhage complicated by acute heart failure. Int J Cardiol. 2014; 176(3):1435-7

52. Mrozek S, Srairi M, Marhar F, et al. Successful treatment of inverted Takotsubo cardiomyopathy after severe traumatic brain injury with Milrinone after Dobutamine failure. Heart Lung. 2016:45(5):406-8.

53. Morelli A, Ertmer C, Westphal M, et al. Effect of heart rate control with esmolol on hemodynamic and clinical outcomes in patients with septic shock: a randomized clinical trial. JAMA. 2013;310(16):1683-91.

54. Wang AY, Akizawa T, Bavanandan S, et al. 2017 kidney disease: improving global outcomes (KDIGO) chronic kidney disease-mineral and bone disorder (CKD-MBD) guideline update implementation: Asia summit conference report. Kidney Int Rep. 2019:4(11):1523-37.

55. Santoro F, leva R, Ferraretti $A$, et al. Hemodynamic effects, safety and feasibility of intravenous esmolol infusion during Takotsubo cardiomyopathy with left ventricular outflow tract obstruction: results from a multicenter registry. Cardiovasc Ther. 2016;34(3):161-6.

56. Isogai T, Matsui H, Tanaka H, Fushimi K, Yasunaga H. Early b-blocker use and in-hospital mortality in patients with Takotsubo cardiomyopathy. Heart. 2016;102(13):1029-35.

57. Madias JE. We need to rethink about prophylactic perioperative b-blocker therapy for Takotsubo syndrome. Cardiology. 2015;130:162-3.

58. Santoro F, Núñez Gil IJ, Stiermaier T, et al. Assessment of the German and Italian stress cardiomyopathy score for risk stratification for in-hospital complications in patients with Takotsubo syndrome. JAMA Cardiol. 2019; 4(9):892-9. https://doi.org/10.1001/jamacardio.2019.2597.

59. Zhang C, Wu Z, Li JW, Zhao H, Wang GQ. The cytokine release syndrome (CRS) of severe COVID-19 and Interleukin-6 receptor (IL-6R) antagonist Tocilizumab may be the key to reduce the mortality. Int J Antimicrob Agents. 2020;55:105954.

60. Moore JB, June CH. Cytokine release syndrome in severe COVID-19. Science. 2020;368(6490):473-4.

61. Liu B, Li M, Zhou Z, Guan X, Xiang Y. Can we use interleukin-6 (IL-6) blockade for coronavirus disease 2019 (COVID-19)-induced cytokine release syndrome (CRS)? J Autoimmun. 2020;111:102452.
62. Luo P, Liu Y, Qiu L, Liu X, Liu D, Li J. Tocilizumab treatment in COVID-19: A single center experience. J Med Virol. 2020;92(7):814-8.

63. Grein J, Ohmagari N, Shin D, et al. Compassionate Use of Remdesivir for Patients with Severe Covid-19. N Engl J Med. 2020;382(24):2327-2336. https://doi.org/10.1056/NEJMoa2007016.

64. Wang $Y$, Zhang D, Du G, et al. Remdesivir in adults with severe COVID-19: a randomised, double-blind, placebo-controlled, multicenter trial. Lancet. 2020;395(10236):1569-78.

65. Bloch EM, Shoham S, Casadevall A et al. Deployment of convalescent plasma for the prevention and treatment of COVID-19. J Clin Invest. 2020; 130(6):2757-65.

66. Duan $\mathrm{K}$, Liu B, Li C, et al. Effectiveness of convalescent plasma therapy in severe COVID-19 patients. Proc Natl Acad Sci U S A. 2020;117(17):9490-96. https://doi.org/10.1073/pnas.2004168117.

67. Shen C, Wang Z, Zhao F, et al. Treatment of 5 Critically III Patients With COVID-19 With Convalescent Plasma. JAMA. 2020;323(16):1582-9. https:// doi.org/10.1001/jama.2020.4783.

68. Li L, Zhang W, Hu Y, Tong X, et al. Effect of convalescent plasma therapy on time to clinical improvement in patients with severe and life-threatening COVID-19: a randomized clinical trial. JAMA. 2020;324:e2010044. https://doi. org/10.1001/jama.2020.10044.

69. Zhao R, Li M, Song H, et al. Early detection of SARS-CoV-2 antibodies in COVID-19 patients as a serologic marker of infection. Clin Infect Dis. 2020: ciaa523. https://doi.org/10.1093/cid/ciaa523.

70. Deng Y, Liu W, Liu K, et al. Clinical characteristics of fatal and recovered cases of coronavirus disease 2019 (COVID-19) in Wuhan, China: a retrospective study. Chin Med J (Engl). 2020;133(11):1261-67. https://doi. org/10.1097/CM9.0000000000000824

71. De Backer O, Debonnaire P, Gevaert S, Missault L, Gheeraert P, Muyldermans L. Prevalence, associated factors and management implications of left ventricular outflow tract obstruction in Takotsubo cardiomyopathy: a twoyear, two-center experience. BMC Cardiovasc Disord. 2014;14:147.

72. Grasselli G, Zangrillo A, Zanella A, et al. Baseline characteristics and outcomes of 1591 patients infected with SARS-CoV-2 admitted to ICUs of the Lombardy Region, Italy. JAMA. 2020;323(16):1574-81.

73. The RECOVERY Collaborative Group. Dexamethasone in hospitalized patients with Covid-19 — preliminary report. N Engl J Med. 2020: NEJMoa2021436. https://doi.org/10.1056/NEJMoa2021436.

\section{Publisher's Note}

Springer Nature remains neutral with regard to jurisdictional claims in published maps and institutional affiliations.
Ready to submit your research? Choose BMC and benefit from:
- fast, convenient online submission
- thorough peer review by experienced researchers in your field
- rapid publication on acceptance
- support for research data, including large and complex data types
- gold Open Access which fosters wider collaboration and increased citations
- maximum visibility for your research: over $100 \mathrm{M}$ website views per year
At BMC, research is always in progress.
Learn more biomedcentral.com/submissions 